\title{
The Impact of Digitalization on the IT Department
}

\author{
Nils Urbach • Frederik Ahlemann • Tilo Böhmann • \\ Paul Drews • Walter Brenner • Florian Schaudel • \\ Reinhard Schütte
}

Published online: 10 December 2018

(c) Springer Fachmedien Wiesbaden GmbH, ein Teil von Springer Nature 2018

\section{Introduction}

In the digital age, innovative technologies such as social media, mobile computing, data analytics, cloud computing, internet of things (SMACIT), and more recently blockchain, artificial intelligence, and virtual reality significantly influence work processes, products, services, and business models. They connect individuals, organizations, machines, and other 'things' in new ways, and they enable novel working, collaboration, and automation models (Urbach and Röglinger 2018). The intensity as well as the speed of the resulting change are remarkable. Most of these digital technologies are not revolutionary on their own, but develop their innovative strength through increased efficiency, significantly better network possibilities, as well as their widespread dissemination and use. By combining the transformational power of these technologies, their

Prof. Dr. N. Urbach $(\bowtie)$

Project Group BISE of Fraunhofer FIT, University of Bayreuth, Wittelsbacherring 10, 95444 Bayreuth, Germany

e-mail: nils.urbach@uni-bayreuth.de

Prof. Dr. F. Ahlemann · Prof. Dr. R. Schütte

University of Duisburg-Essen, Essen, Germany

Prof. Dr. T. Böhmann

University of Hamburg, Hamburg, Germany

Prof. Dr. P. Drews

Leuphana University of Lüneburg, Lüneburg, Germany

Prof. Dr. W. Brenner

University of St. Gallen, St. Gallen, Switzerland

Dr. F. Schaudel

McKinsey \& Company, Frankfurt, Germany business impact is even greater (Urbach and Ahlemann 2018). For companies, this development often poses a significant challenge. To succeed in this changing competitive environment, companies must unfold the potential of digital technologies in their business strategies, transform their work routines, processes and structures, rethink their business models as well as manage and govern IT infrastructures that are central to their value proposition (Legner et al. 2017).

Digitalization has therefore increased the importance of information technology (IT), and it has transformed the demands placed on organizations' IT functions. The business activity does not only become more efficient, but it is also no longer imaginable without IT. Since information technologies are now applied to realize innovations for businesses-something that will increase in the future-IT functions are required to cooperate proactively and early on with business departments to be able to develop and implement such innovations jointly. Besides ensuring regular IT operations, IT functions are increasingly required to identify technological innovations proactively and rapidly transfer them into marketable solutions, thereby directly contributing to the company's central value proposition (Urbach et al. 2017).

Chief information officers (CIOs) often like to address the digitalization topic themselves. This is not unexpected, because their departments are responsible for information technology in companies, and digitalization promises to expand their sphere of activity, or at least to strengthen their role. However, many CIOs and IT executives encounter problems. Their IT departments-in their current setups-are often seen as pure service providers with no dedicated innovation skills. The business departments often act independently from the IT department when developing IT-based business and process innovations. This is not 
surprising, as many IT departments are still very technology-oriented with little business know-how. Creativity, entrepreneurship, and innovation activities often have merely a shadow existence in an industrialized IT department that is focused on reliability and stability. Most IT departments are structurally and procedurally unprepared to play a special role in digital transformation. Past cost optimizations also contribute to this: Their capacities are rarely sufficient to test and implement new ideas beyond daily business (Urbach and Ahlemann 2018). Consequently, many IT managers feel uncertain regarding their positioning in the digital age and their approach to digital transformation. In some cases where CIOs could not extend their role from pure technologists to business strategists, companies have even created a chief digital officer (CDO) position to drive digital transformation, placing additional pressure on the IT department (Sing and Hess 2017).

This connects to previous discussions in this section (Legner et al. 2017; Riedl et al. 2017) that aimed to initiate reflections on how the Business and Information Systems Engineering (BISE) community can leverage the opportunities and develop and/or maintain thought leadership of digitalization. The focus is on the changing role of the IT department in the digital age. For that purpose, we summarize the contributions and subsequent discussions of two panels at the 13th International Conference on Wirtschaftsinformatik (WI 2017) in St. Gallen, Switzerland, and the Multikonferenz Wirtschaftsinformatik 2018 (MKWI 2018) in Lüneburg, Germany. Specifically, BISE researchers and practitioners convey their perspectives on the following questions:

- What is the impact of the current wave of digitalization on companies' IT departments? Which new requirements must IT departments fulfill?

- Are IT departments prepared for the new challenges arising from digitalization? Does the IT management have to reposition itself and, if so, how? Which (new) capabilities are required to play an active role in the digital transformation?

- How can the BISE community support IT departments in their changing role, and how can they help IT management play a major role in digital transformation? Do the recent developments require a shift in research and teaching? What are the consequences for the discipline?

Prof. Dr. Nils Urbach University of Bayreuth

\section{IT Expertise Everywhere: Why the Single IT Department will Soon be History}

IT has come a long way since its initial use in business environments. At each stage of this journey, specific technological, organizational, and market drivers changed the way in which IT is organized and managed. For instance, the advent of personal computing dramatically changed the way IT specialists interacted with business users. Likewise, client server computing allowed for new forms of business applications and had tremendous effects on IS management. In the following, I identify and describe some of the major forces that impact today's IT departments and that will probably continue to do so in the foreseeable future. I will then outline my view of a future IT department.

One of the most important but rarely mentioned drivers is that IT skills have spread across all parts of the population, specifically among the current workforce. This has a significant impact on how IT needs to be managed and organized. It means that systems with little to medium complexity no longer require extensive training-in most cases users approach new solutions intuitively. Advanced users can create ideas for innovative IT solutions and develop preliminary designs. In fact, as they are often equipped with years of IT experience, they can largely configure and manage (packaged) software on their own. The consequences are clear: We need fewer specialists for more IT-related tasks, and processes like technology training and qualification lose importance.

A second major driver is that IT has improved significantly in terms of quality and performance. Today's systems are (on average) more reliable than 20 or 30 years ago. Moore's Law appeared to be largely true. We are experiencing an ongoing process of technological standardization that fosters interoperability and connectivity, fueled by market consolidation, market pressure, and standardization committees worldwide. This trend has had a profound impact on the IT industry by allowing easier outsourcing, enabling cloud computing, and driving the external procurement of IT services. This applies to almost all parts of the software/hardware stack-from infrastructure and via platforms to applications.

The third driver on my list, and possibly the most prevalent digitalization characteristic, is the move "from process to product," which describes the gradual shift from "mere" process automation as the main domain of business IT to its increasing involvement in the design of new products, services, and even business models. Early IT's potential was aimed at automating computing-intense tasks. However, advancing computer technology, declining hardware prices and inexpensive wide area networks allowed new opportunities to emerge for IT-enabled value 
propositions for customers. This implies that IT departments must collaborate with other business functions in novel ways: $R \& D$, as well as marketing and business development, are no longer mere service consumers of the IT department. Instead, they have become an eye-level partner producing digital innovations that strengthen the firm's competitive position. However, IT departments can only contribute to such innovations if they are closer to the business departments and more flexible-hiding behind SLAs is probably not the way to go. It is not surprising to see new organizational designs for bringing about IT-enabled innovations like digital innovation hubs or digitalization centers. The increased strategic relevance of IT means that security and business continuity management are more important than ever before, and implies a shift from a technical interpretation of these tasks to a more holistic and strategic perspective.

The fourth driver links to the previous one and is partly the result of the increased use of IT in all parts of today's value chains. In general, business has accelerated significantly and, accordingly, innovativeness and market dynamics. Innovation cycles have shortened, which has led to strong pressure on firms' IT-driven research and development activities. In ever-shorter time intervals, organizations offer new or improved products, services, and even novel business models. Firms must constantly adapt to survive. This means that innovation and change have become the new operating model requiring new and effective forms of management concepts, such as agile project management and design thinking.

What are the consequences of these strategic drivers? What will the future IT department look like? I think we will see classic IT departments shrinking, because companies will assign more of their IT professionals to business departments or specific digital innovation units. This is not surprising given that IT has become more important for product, service, and business model development and because IT development has become increasingly agile and end-user/customer-centric. Beyond this, there will be less need for infrastructure specialists due to outsourcing and public cloud computing. In the long term, operating an own data center with the relevant IT infrastructure will only pay off for very large firms and specialized service providers.

What else? I anticipate that future IT departments will have a more strategic coordination role. They will be responsible for seven critical management tasks: (1) investment and portfolio management, (2) enterprise architecture management, (3) security and business continuity management, (4) vendor/supplier management, (5) consulting and development support, (6) (support of) digital strategy development, and (7) IT governance. These management tasks ensure a structured and coordinated development of corporate IT that is secure, reliable, aligned, cost-efficient, and flexible. Given its strategic relevance, I anticipate that the IT department of the future will be located close to the management board and not on the third or fourth level of the organizational hierarchy.

Should we be scared? I don't think so. As a research discipline, we will remain relevant, but we should probably accept that some of our neighboring disciplines, such as the marketing field, will deal with IT topics more regularly. On the other hand, we can be self-confident, because the future will be more "IT-enabled" than ever before, giving our research and teaching legitimacy- provided we have something relevant to offer.

Prof. Dr. Frederik Ahlemann University of Duisburg-Essen

\section{The Triple Jump Towards IT for the Digital Age: Data-Driven Agility, Product Centricity and Business-IT Convergence}

The current wave of digitalization is driven by customers' and consumers' changing expectations. During the previous years, IT departments professionalized their skills in planning, developing, and running standardized and efficiency-oriented IT solutions at low costs. IT departments' core customers were internal business users and business units. The core contribution of IT was to provide an efficient and integrated set of business solutions to these customers. Predominant IT management frameworks emphasize top-down business-IT alignment and high service quality at low cost and with low risk. As a result, planning processes worked in annual cycles, and updates could only be rolled out a few times a year.

This predominant model is increasingly at odds with the IT needs of digital ambitions. Performance measurement for IT departments is shifting towards new categories such as time to market, realized innovations, new business models and consumer/customer satisfaction. Furthermore, disruptive business models and the increasing influence of the large internet and tech companies are increasing the pressure to strategically rethink the role of IT. With the digitalization wave, IT is finally receiving top management attention, also in non-IT companies.

Our studies on digital excellence (Drews et al. 2015; Böhmann et al. 2016) show that building these capabilities is a major strategic shift for IT in enterprises. We see three major areas of transformation: a data-driven and agile way of working (data-driven agility), a shift from projects to products as the main organizing logic of IT, and the convergence of business and IT.

Many companies seek to transform the way of working in their IT departments, and increasingly also in their 
business units, to enable exploration and innovation of new digital products and services. For IT departments, the focus is shifting from serving internal customers to creating and operating these digital products and services for external customers. Given the increasing volatility of the digital age, the goal is to foster an entrepreneurial spirit and to facilitate innovation.

Core to this new way of working is a constant mode of exploration and learning, for instance as advocated by the lean startup approach (Ries 2011). Lean startup sees the iterative creation of digital products and services as a constant mode of learning. The goal is to learn about customer needs based on real-world customer engagement with step-by-step improved versions of a digital product or service. This customer engagement creates qualitative and quantitative data to validate hypotheses regarding the design of such products and services. Teams adopt agile and lean methods like Scrum and Kanban to rapidly change and test new versions.

We characterize this new mode of working as datadriven agility. In our research, we found cases in which companies seek to transform the entire enterprise to these new ways of working. Other firms adopt such approaches only for innovating, developing, and improving customercentric digital services. In these firms, two or even multiple modes of IT design and delivery co-exist. While the new way of working is well understood on the level of individual teams and projects, data-driven agility in large environments requires role players to rethink organizational and management practices. Strategic direction must be balanced with bottom-up innovation. Traditional methods for setting directions (for example through IT project portfolio management) must be adapted to remain useful in the context of a new way of working.

With the focus on delivering digital products and services, the organizing logic of IT is shifting towards what has come to be called "products" instead of projects. The term "product" may be misleading - it refers to a loosely coupled piece of IT that ideally has a clearly defined (external) user or customer. In the context of a digital shopping service, the search and navigation features can be aggregated to a product. Such "products" allow assigning end-to-end responsibility for the design and the ongoing operation to a team. To enable the team to make these decisions, such teams incorporate different skill sets, for instance software development, user interface design, data analytics, and product management.

Finally, and as a contrast to traditional projects, such a product-centric organization is a standing organization without time limitations. While project teams are dissolved after the project's end, product teams remain responsible for the product across the entire lifecycle. Together with delegated authority and the interdisciplinary skill set, this organizing logic can foster entrepreneurial ownership for the product created in the team. A product orientation can also be applied beyond the team level. Spotify, for example, has "tribes" that comprise multiple teams. These tribes have end-to-end responsibility for a larger business domain, and companies in other industries have recently adopted the concept.

Realizing a product-centric organization is often only one step in the direction of a stronger convergence of IT and business. True end-to-end responsibility for digital products and services can only be achieved with an integrated mode of making business and IT decisions. Leading companies overcome the gap between business and IT by shifting towards a "BizDevOps" model (Gruhn and Schäfer 2015; Horlach et al. 2018). BizDevOps refers to the integration of business, development, and operations for a digital product or service in one unit, for example an interdisciplinary team. Instead of the traditional alignment of IT and business as two separate entities, BizDevOps dissolves the boundaries between business and IT. If companies follow this mode, the IT department as we know it might not continue to exist in the future. If companies transform only parts of their business into this new mode, the IT department is likely to continue existing as in previous years.

Taken together, data-driven agility, a product-centric organizing logic, and the increasing convergence of business and IT create huge opportunities and challenges for traditional IT departments. Coming from a logic focused on internal customers, standardization, and efficiency, this transformation requires intermediate steps. It is not surprising that many organizations have created digital (business) units that spearhead these changes. There are, however, examples of transformation towards these new approaches that apply to the entire organization. The ongoing transformation of the IT department is an innovation endeavor for which blueprints and principles must still be developed by the joint efforts of practice and research.

Prof. Dr. Tilo Böhmann University of Hamburg

Prof. Dr. Paul Drews

Leuphana University of Lüneburg

\section{Good News and Bad News: The Future Role of the Chief Information Officer}

There's good news and bad news concerning the future role of the chief information officer (CIO). The good news is that CIOs will continue to play an important role in companies, and will even become more influential. The bad 
news is that many of today's CIOs are overwhelmed by the demands of the future, and will not personally benefit from this development unless they transform themselves significantly.

According to these predictions, I will present my statement in two parts. In the first part, I will address the question of why the CIO role will become more important and what kinds of tasks chief information officers will take on in the future. In the second part, I will examine why many CIOs are overwhelmed by the prospect of the future development of their position, and what they should ideally do to address these changes.

Why will the CIO position continue to be important and why will its influence increase? I define the process of digitalization as the intensified exploitation of information and communication technologies in all areas of the economy and society. In previous decades, the CIO's task has been to attend to the administrative duties of information processing and their efficiency. The focus was on automating back office processes. Mobile data processing and customer-oriented processes were also added with the advent of internet usage and e-commerce.

Besides automating these processes, questions of sourcing, software development and infrastructure were addressed. Excellent processing quality and lowering costs were the key measures for all these tasks. Many CIOs met these challenges with high levels of competency. Digitalization greatly expands the field of application for information technology. Digital and digitized products, as well as digital services, are developed and sold. New digital business models are developed, and for many companies, the digital front-end is the central presentation platform for customers. Data that was in the past merely seen as a means to an end is suddenly an important resource for a company's strategic development.

In the digital age, software development is becoming a major source of innovation and the core competence of digital companies. Supporting the speed and flexibility of software development becomes a task for executive management. In addition, innovation through information and communication technology is an important subject in all areas of the company and is taken charge of on an individual basis.

In conclusion, it can be said that in this digital age, almost no strategy or decision-making occurs without a significant input from information and communication technology. Innovative and professional experts in the areas of information and communication technology are needed to develop corresponding solutions and to operate these reliably. I would even go so far as to say that information technology skills in management are of essential strategic importance, and will continue to be so in future.
The future belongs to chief information officers who can take on and fill this position.

Why is it that many of today's active CIOs are overwhelmed by future demands and will not personally benefit from this positive development? Over the last few years, I have seen more than 100 presentations by CIOs and companies about the process of digitalization. Without precise statistical analysis on my part, I would say that twothirds of the presenters used the term digitalization as the new identifier for information projects. Website optimization, the development of Internet sales (e-commerce), or the adoption of standard software all come under the umbrella of digitalization projects. Critical questions, such as those relating to future business models, or from a technical perspective, the comprehensive use of cloud technology, are not addressed. Numerous CIOs use digitalization as a place from which they can position their traditional IT projects, essentially wrapping old ideas in new packaging.

The deficits I observe in many CIOs can be divided into content-based and methodical challenges. Content-based challenges refer to the comprehensive use of information and communication technology. Developments in the car industry are a good example. Vehicles are increasingly developing into cyber-physical systems-in other words, digitized products. Innovation increasingly occurs by using data that has been collected from sensors in a vehicle, such as ultrasound, radar, cameras and, in future, also lidar.

In the future, the central processing unit in a vehicle will be almost as important as its motor. Beyond software developments, the software in vehicles also must be managed and updated. The CIO is predestined to manage and update the software. To complete this task, CIOs need to be skilled in the field of embedded software systems. They often do not have this knowledge and are therefore also not involved in the conception of these strategic solutions for the automotive industry.

Similar questions arise regarding the machine industry and through the growth of the Internet of Things, for example in the finance and health sectors. The implications for chief information officers are clear: either they develop the necessary expertise personally and in their team, or they will eventually be replaced.

From a methodological perspective, demands are also changing quickly. Approaches to the method of "design thinking" are almost symptomatic of this. Many classic CIOs have had an indistinct awareness of this method for many years. Unprofessional discussions are held about design thinking and other modern innovation methodologies, such as crowdsourcing, without any real examination of the advantages of these methods. At best, new methods were tested in unimportant areas of the company. 
CIOs who operate like this are then taken by surprise when a department, for example marketing, uses these new methods and suddenly develops customer-oriented, innovative solutions. To "kill" the new solutions, a discussion about responsibility often follows, instead of finding a constructive and consistent solution for the use of these new methods. There are many other examples of this "nonengagement" with new methods, but space is limited.

I have worked with chief information officers for almost 40 years, and held the position myself for two years. I am convinced that many of my colleagues have the ability and the will to face and overcome these new challenges. They will only succeed, however, if they subject themselves as well as their field to a sober and realistic analysis, and implement the necessary steps based on the results.

A final note: Learning cannot be delegated. Chief information officers who are interested in successfully progressing through this transformation will have to invest a significant part of their working hours in training and development. Lip service won't be enough.

Prof. Dr. Walter Brenner University of St. Gallen

\section{Digitalization Might Change the World, but Does it Really Fundamentally Change how IT has to be Managed?}

If we look at what IT is typically expected to contribute to the success of a company, three things often come to mind first: Keeping the lights on, ensuring they will also stay on in the future, and helping "the business" to maximize the value generated from IT. If we look at these tasks individually, we can see that while the bar for good practice might become higher and the complexity might increase, the core challenges remain surprisingly similar:

- Keeping the lights on: One of the key impacts of digitalization on the IT function is the unprecedented speed of change in IT. While only 20 years ago quarterly release cycles were the norm and advanced IT units of large companies managed to do monthly releases, today even daily builds are kind of slow compared to the speed of leaders in IT agility. Serviceoriented architecture, agile software development, DevOps and other more recent developments help tremendously to master the challenges of the new IT requirements, but have also increased the complexity of IT and therefore of IT management. To mention just one example: While the latest advances in robotics process automation (RPA) have undoubtedly brought huge benefits for business efficiency, they also transformed virtually every screen to a formal interface. Experienced CIOs who were around in the $90 \mathrm{~s}$ and $00 \mathrm{~s}$ when all "unofficial IT" was consolidated back into "official systems" are already planning how to reconsolidate the new robotics some years from now.

- Ensuring long-term stability: The new pace of change has brought great momentum for many IT departments - and perhaps it is the required external stimulus many organizations needed to overcome the proverbial "host mindset" that in some cases led to encrusted structures. With new technologies being required, new people with different skills and mindsets enter IT units. While managing the talent pool in their organization has always been an important job of IT management, this has now become perhaps the most important capability. Finding and attracting new, young, appsavvy talent is difficult for an organization with a different mindset. Also, the integration into the organization and bridging cultural gaps between the traditional and the new workforce are constant struggles. One of the biggest challenges is yet to come: Retaining the new talent and making sure that the required capabilities to maintain the IT are preserved over the entire lifecycle of systems and service. While the gig economy definitely helps to find the people for a specific project or assignment, it also makes it more difficult to remain attractive for these talents over the 5, 10 or 20 years that an individual system will be required. If you thought 10 years ago that finding and retaining Cobol or PL/1 programmers was challenging, think about Ruby on Rails or Angular developers in 5-10 years.

- Help maximize value from IT: Potentially the biggest change that digitalization has brought along is the fact that IT has become a core part of the value proposition and business model in almost any industry. If it has ever been a valid position of IT to be a commodity service provider in the back office that is separated from business, this is not the case anymore. Even the separation between functional IT and product IT that many manufacturing companies had adopted in the past seems to be more difficult in times of app-enabled business models and hybrid customer journeys. As business is often lacking the transparency concerning which technologies are available and how they can best be applied to solve specific business issues, the IT department has a stronger role than ever, not only in advising the business on how requirements can be fulfilled, but also in originating new ideas and developing new products and services.

Looking at these changes from the perspective of the BISE community and asking about implications for 
research and teaching future generations of IT leaders, three imperatives come to mind:

- Technological foundations are more important than ever: As individual technologies will continue to change rapidly, the odds are that future technology leaders will be confronted with a completely different technology stack than what they have learned during their education. Basic concepts in infrastructure, application development, architecture, and security are however here to stay. Acquiring robust foundations in these fields is key to being prepared for the future.

- (People) Management skills need to be strengthened: While BISE graduates traditionally have excellent technical skills and a robust education in general economics, many of them are not specifically trained on HR topics. This is in line with the fact that many BISE departments at universities do not have a particular research focus in HR. As attracting and retaining adequate talent is key for keeping the lights on in the long term, it might be necessary to place more emphasis there.

- Future IT leaders need (business) domain knowledge: As IT is becoming a key part of the value delivery to the customer in almost any industry, it is of utmost importance for IT leaders to have deep domain knowledge of the industry they work in. One must discuss to what extent the traditional model of the more or less "industry-agnostic CIO" with a strong technology management profile independent from a specific industry will remain valid. At least those companies that chose to combine CIO and CDO roles need deeper insights into the specific business requirements. The BISE community must therefore discuss whether the predominant model of training generalist IT management talents is the best way of going forward, or whether the next generations need deeper individual industry expertise.

Overall, one could conclude that good IT management remains good IT management, even in a digital world. What may have changed, is that good IT management might be more important than ever before, and the consequences of a weak IT function can be even more drastic. Specifically for SMEs for whom it traditionally has been even more challenging than for large companies to attract and retain top IT talent, these changes might turn out to be critical for the future.

Dr. Florian Schaudel McKinsey \& Company, Frankfurt
6 Creating the Future of IT Departments and Academic Research in IT in the Digital Era: A Plea for Integrational Thinking

\subsection{From one Element in the Division of Labor to a Fully Integrated Point of View}

The existence of departments in organizations is not logically necessary. Division of labor renders task coordination as an essential goal of organizational design. The development of the IT department shall not be portrayed here (for that matter, see Urbach and Ahlemann 2018; Masak 2006); however, due to the generally presumed requirement of labor specialization, the "detachedness" of the IT department seems to be scarcely questioned.

The term "IT department" subsumes the entirety of tasks and the roles responsible for them that are associated with the use or provision of IT. In the current discussion, the question arises as to whether digitalization is changing the way the IT department should be designed. This requires answering, first, whether digitalization today is coming along with different effects in organizations than in the past; second, whether the requirements regarding IT have significantly changed to achieve the intended effects; and third, whether the process from requirements to effects-the implementation process of requirementsmust be adapted to correspond with the results of the investigation in the first two steps.

1. Analysis of the effects in companies: The effects of information technology have been intensively studied in IS research, so that in a general sense, there are hardly any IT effects that are not already known. However, in the course of digitalization, domains are penetrated that had been barred from IT before-we can observe a broadening of IT. At the same time, established areas of application experience an intensification of their IT usage, for instance by fully automating previously only partly or non-automated tasks (substituting the dispositive factor), or by improving the quality of support through IT-we can observe a deepening of IT. It is reasonable to assume that, as part of digitalization, the broadening and deepening effects will be further combined and amplified, without a real novelty of the effect being noticeable. An exception might only apply to the aspect of organizational culture which might indeed experience unprecedented effects.

2. Analysis of the requirements regarding IT: If effects are not new but merely more comprehensive, one will also observe an increasing volume of requirements and their broader scope on many different areas. Solutions to those demands are known (as the demands 
themselves are not novel), however less common (as they have not been as pervasive). A previously simple coordination problem between those raising the demands and those fulfilling them will therefore be more expansive. However, it is not to be presupposed that those demands cannot be formulated in an independent IT department.

3. Analysis of the implementation of demands: Located between the effects on the one hand and the requirements causing those effects on the other hand, is the implementation of the requirements through the IT department. Irrespective of the concrete organizational model, in the past it was the pivotal task of the IT department to fulfill the requirements of the business units. With the increasing number of technologies available on the market and the increasing number of technologies required to implement the requirements, while being confronted with an ever-increasing timebased competition, this pivotal task can however only be accomplished if the organizational model allows short and frictionless processes in the IT department.

The satisfaction of companies with their IT departments has been the subject of intensive and controversial discussions all along. The debate not only revolves around the IT department itself, but transcends to the outputs of the IT department and the expectations on software products and their return, considering the associated investment.

We must therefore ask whether the autonomy of the IT department is economically imperative, and if so, how to design the best possible solution for the coordination problem of a company. It should be noted that this question cannot be universally answered for all companies in a "one size fits all" fashion.

The role of IT and the role of the IT department are two disparate aspects. It seems preposterous to derive a change just from growing relevance. We find ourselves at the crossroads of a world based on the division of labor; the IT department will have to be deprived of its autonomy. Resulting from the relationship between requirements, implementation, and effect, as described above, the process idea in today's digitally dominated value chains superimposes the idea of resource efficiency (e.g. Frese et al. 2012). Consequently, business units are increasingly provided with process owners whose authority includes the responsibility for IT products. Therefore, the best IT department in a company might be the one that offers as much digitalization as possible and as little IT department as necessary. This would lead to a reintegration of the IT department's tasks into the organization, but only as much as IT complexity allows.

\subsection{How to Stop Dashing Expectations}

IT departments are overwhelmed with the previously outlined challenges that are documented in the two categories of volume of requirements and IT complexity. They will not be able to fulfil the task, because an IT department in the narrower sense will always tend to implement requirements by using technology, rather than embracing entrepreneurial innovation. Therein lies the main problem which is co-responsible for the productivity paradox: the artificial separation between business units and the IT department leads to unnecessary demands (in the context of the previous system logic approximately implemented or insufficiently usable).

In my view, there are three conceivable developments: Either the IT department secludes itself and merely becomes the supplier of a service, or it follows a pro-active approach and is taken up in the business units, or it assumes the dominant role for shaping the company and therefore reverses the role between business units and the IT department. Depending on which direction prevails, a new set of capabilities becomes necessary in the departments. The direction mentioned first is no different from what is still common practice. In the other two directions, there will not be an IT department that does not have knowledge of the business domain. In my view, IT departments will have to master those challenges - the first alternative might be sufficient in some companies, but will not adequately support serious digitalization efforts in most companies.

\subsection{The Fall of BISE and how to Prevent it: Where is} the Future in the Triangle of Computer Science, Business Administration, and BISE?

BISE should play an active role in this change; however, it could be self-critically questioned whether the changes in the discipline are sufficient in research and teaching. Due to the changes in companies, BISE must assert itself against what may be the largest challenge since its founding years. Research and teaching are still too much characterized by the separation of business administration, computer science, and BISE. The analysis of the first set of questions indicates that IT departments must be less detached to be successful. This might not be the best solution for a specialized and institutionalized research world. But further differentiation cannot be upheld for business administration (Schütte 2014; Gloger 2016; Schröder and Barth 2018; Backhaus and Paulsen 2018), as-for the ministries of science - the legitimation of the institutions originates from teaching requirements and not from research results.

The BISE community is the result of a scientific sociological process. The empirical and the epistemological 
object of BISE only differ from business administration if the latter does not subsume all BISE's key questions under its umbrella of "business actions." Through the analogy of positioning the IT department, as we did above, one could advocate the thesis that the best BISE discipline is the one that contributes to renovating the business administration discipline.

Digitalization is not a phenomenon, but primarily an economic question - and many seem to be unaware of its many opportunities. Information in companies has been discussed in the context of production factors (autonomous production factor vs. integrated constituent). Along with the business administration discipline, the BISE discipline is increasingly exposed to challenges from computer science. The solution lies in focusing on its key questions in the context of digitalization: construction, usage, and effects of IT systems in organizations.

The discipline has neglected the organization for too long, even though only thereby the economic value of IT is created. BISE occasionally appears like the IT department in the company: too far away from the organizational aspects and therefore from business administration as its mother discipline. This is where the danger originates that-if the business administration discipline recognizes this opportunity and claims it for itself and computer science takes over the construction of IT systems-BISE will not only lose its relevance, but also its rigor.

Prof. Dr. Reinhard Schütte University of Duisburg-Essen

\section{References}

Backhaus K, Paulsen T (2018) Vom Homo Oeconomicus zum Homo Digitalis-Die Veränderung der Informationsasymmetrien durch die Digitalisierung. In: Bruhn M, Kirchgeorg M (eds) Marketing Weiterdenken-Zukunftspfade für eine marktorientierte Unternehmensführung. Springer, Heidelberg, pp 105-122

Böhmann T, Drews P, Zolnowski A (2016) Datengetriebe Agilität: Auf der Erfolgsspur zur digitalen Exzellenz. Sopra Steria Consulting, Hamburg
Drews P, Meyer-Blankart C, Böhmann T (2015) Digitale Exzellenz: Eine Bestandsaufnahme zur Digitalisierung deutscher Unternehmen und Behörden. Sopra Steria Consulting, Hamburg

Frese E, Graumann M, Theuvsen L (2012) Grundlagen der Organisation: Entscheidungsorientiertes Konzept der Organisationsgestaltung, 10th edn. Springer, Heidelberg

Gloger A (2016) Betriebswirtschaftsleere-Wem nützt BWL noch? Verlag Neue Zürcher Zeitung, Frankfurt am Main

Gruhn V, Schäfer C (2015) BizDevOps: because DevOps is not the end of the story. In: Fujita F, Guizzi G (eds) International conference on intelligent software methodologies, tools, and techniques. Springer, Basel, pp 288-298

Horlach B, Böhmann T, Schirmer I, Drews P (2018) IT governance in scaling agile frameworks. In: Proceedings of the Multikonferenz Wirtschaftsinformatik, Lüneburg

Legner C, Eymann T, Hess T, Matt C, Böhmann T, Drews P, Maedche A, Urbach N, Ahlemann F (2017) Digitalization: opportunity and challenge for the business and information systems engineering community. Bus Inf Syst Eng 59(4):301-308

Masak D (2006) IT-Alignment: IT-Architektur und Organisation. Springer, Heidelberg

Riedl R, Benlian A, Hess T, Stelzer D, Sikora H (2017) On the relationship between information management and digitalization. Bus Inf Syst Eng 59(6):475-482

Ries E (2011) The lean startup: how today's entrepreneurs use continuous innovation to create radically successful businesses. Random House, New York

Schröder H, Barth K (2018) "Betriebswirtschaftsleere" von Axel Gloger-Wem nützt das Buch?, https://www.marketing.wiwi. uni-due.de/fileadmin/fileupload/BWL-MARKETING/APOWI/ 4_Publikationen/Essener_Kontrapunkt/Essener_Kontrapunkt_ 2018_1_-_Betriebswirtschaftsleere_-_wem_nu_tzt_das_Buch_ 20180306.pdf. Accessed 10 July 2018

Schütte R (2014) Hat die Betriebswirtschaftslehre in Zeiten der Digitalisierung noch eine Zukunft? https://www.zu-daily.de/ daily/tiefenbohrung/2013/schuette-betriebswirtschaftslehre-unddigitalisierung.php; https://www.iis.wiwi.uni-due.de/forschung/ veroeffentlichungen/vortraege-interviews/antrittsvorlesung-zep pelin-universitaet-friedrichshafen-1331. Accessed 10 July 2018

Sing A, Hess T (2017) How chief digital officers promote the digital transformation of their companies. MIS Q Exec 16(1):1-17

Urbach N, Ahlemann F (2018) IT management in the digital age-a roadmap for the IT department of the future. Springer, Heidelberg

Urbach N, Röglinger M (2018) Digitalization cases-how organizations rethink their business for the digital age (editorial). Springer, Heidelberg

Urbach N, Drews P, Ross J (2017) Digital business transformation and the changing role of the IT function. MIS Q Exec 16(2):ii-iv 